\title{
PROMOÇÃO DE SAÚDE NA ESCOLA: REINVENTANDO ESTRATÉGIAS DE CUIDADO COM ADOLESCENTES
}

\author{
HEALTH PROMOTION AT SCHOOL: REINVENTING ADOLESCENT \\ CARE STRATEGIES
}

\author{
Lilian Maria Borges ${ }^{1}$ \\ Cynthia Conceição Schmidt Campanati ${ }^{2}$
}

\section{RESUMO}

Relato de experiência desenvolvida por equipe de Saúde da Família de um município da região metropolitana do Rio de Janeiro com o objetivo de fomentar o cuidado em saúde mental com adolescentes em ambiente escolar com vistas à redução de vulnerabilidades e violências. A intervenção ocorreu com seis turmas do ensino fundamental de uma escola pública por meio de encontros semanais, tendo como método a roda de conversa. Como benefícios diretos ao público-alvo do projeto, os resultados apontaram construção de vínculos e fortalecimento de criticidade e autonomia. Efeitos indiretos também foram observados, como uma prática profissional mais planejada, refletida e engajada, fortalecimento do trabalho intersetorial na região e aprofundamento dos debates sobre a saúde mental no nível da atenção primária em saúde. A experiência registrou o potencial da parceria entre rede de saúde e escola para o cuidado integral aos usuários mediante integração de saberes e ações.

Palavras-chave: Promoção da saúde; Violência; Vulnerabilidade; Escola.

\begin{abstract}
This article is a report on an experience developed by a Family Health Team in a municipality in the metropolitan region of Rio de Janeiro to promote mental health care for adolescents in a school environment to reduce vulnerabilities and violence. The intervention took place in six elementary school classes at a public school through weekly meetings, using the conversation circle as a method. The direct benefits to the project's target audience include the construction of bonds and strengthening of criticality and autonomy. Indirect effects were also observed, such as a more planned, reflected, and engaged professional practice, strengthening of intersectional work in the region, and deepening debates on mental health at the level of primary health care. The expeience registered the potential of the partnership between the health network and school for comprehensive care through the integration of knowledge and actions.
\end{abstract}

Keywords: Health promotion; Violence. Vulnerability; School.

\footnotetext{
${ }^{1}$ Atualmente é Professora Adjunta do Departamento de Psicologia e o Programa de Pós-graduação Stricto Sensu em Psicologia da Universidade Federal Rural do Rio de Janeiro. Doutora em Psicologia pela Universidade de Brasília (UnB). e-mail: limaborgesg@gmail.com

2 Mestra em Saúde Pública pela ENSP/FIOCRUZ. Especialista em Atenção Psicossocial à Infância e Adolescência pelo IPUB/UFRJ. Graduada em Psicologia pela Universidade Salgado de Oliveira. e-mail: cy_psi@yahoo.com.br
} 


\section{Revista \\ Debates Insubmissos}

\section{INTRODUÇÃO}

Esse trabalho relata a iniciativa de uma equipe de Saúde da Família no âmbito de um projeto de promoção da saúde em contexto escolar construído como forma de enfrentamento e prevenção às violências em um município da Região Metropolitana do Rio de Janeiro. Tratase de uma intervenção que fomentou práticas de cuidado primário em saúde mental como imagem-objetivo, conceito este utilizado por Teixeira (2010) como um norte para o planejamento das ações em saúde, de modo a visualizar daquilo que se deseja atingir. As estratégias de Prevenção da Violência e de Promoção da Cultura de Paz tiveram destaque como atividades coletivas previstas no escopo das ações em atenção primária à saúde. A Política Nacional de Atenção Básica (PNAB) (BRASIL, 2017) e a Política Nacional de Promoção da Saúde (PNPS) (BRASIL, 2006; 2014) direcionaram e organizaram a análise da experiência em pauta.

De acordo com Buss e Pellegrini Filho (2007), no campo da saúde pública brasileira, houve historicamente um esforço para mudanças no paradigma da assistência, antes voltada às individualidades, focada na doença e marcada pela lógica biomédica, para um primado do cuidado, dirigindo-se a atenção à saúde integral das pessoas, grupos e populações, orientada pelo olhar biopsicossocial. Os autores destacam que essa concepção de cuidado se ancora no entendimento contemporâneo de que a saúde é um processo extenso, marcado e afetado por diversas esferas da vida, o que inclui os chamados determinantes e condicionantes sociais da saúde.

Pautando-se por essas mudanças conceituais, na esfera da Atenção Básica (AB) encontram-se práticas de cuidado voltadas à promoção de saúde, prevenção de agravos, vigilância em saúde, diagnóstico e tratamento de doenças, redução de danos e cuidados paliativos. A PNAB apresenta os princípios e diretrizes preconizados para este nível de atenção, partindo do pressuposto de que os diversos fatores que afetam as condições de saúde das pessoas podem ser abordados em seus contextos de vida diária, visando o fortalecimento da cidadania e maior autonomia (BRASIL, 2017). De fato, os cuidados primários se configuram como a porta de entrada do sistema de saúde e primam pelo trabalho no território 


\section{Revista
Debates Insubmissos}

mediante adscrição da clientela e valorização do acolhimento e vínculo com os usuários (STARFIELD, 2002).

Assim, a Saúde da Família é situada como a estratégia principal para expansão e afirmação da $\mathrm{AB}$ e abrange a atuação das Equipes de Saúde da Família (eSF), que realizam os trabalhos nos territórios, no contato cotidiano, direto e continuado com os usuários, sendo constituídas por profissionais de formação mais generalista. Incluem, minimamente, médico, preferencialmente da especialidade medicina de família e comunidade; enfermeira, preferencialmente especialista em saúde da família; auxiliar e/ou técnico de enfermagem e agentes comunitários de saúde (ACS). De acordo com a Portaria MS 2435/2017 (BRASIL, 2017), também poderão compor a equipe o agente de combate às endemias (ACE) e os profissionais de saúde bucal: cirurgião-dentista, preferencialmente especialista em saúde da família, e auxiliar ou técnico em saúde bucal. Essas equipes de referência devem operar de modo articulado e integrado com as equipes multiprofissionais da Atenção Básica (eAB) e do Núcleo Ampliado de Saúde da Família e AB (Nasf-AB). A referida Portaria estabelece que as equipes de apoio sejam constituídas por especialistas em diferentes áreas do saber, prestando, dentre outras funções, apoio matricial aos profissionais das equipes mínimas, do que decorre a necessidade de colaboração de, pelo menos, um profissional da área de saúde mental (BRASIL, 2017).

A despeito de sua importância, a implementação da PNAB, em sua completude, ainda se configura como desafio, pois existe um quadro organizacional e de infraestrutura que segue sem dialogar de modo mais efetivo com os princípios e diretrizes da regulamentação. Nessa direção, Campanati (2018) observou uma importante lacuna entre o lugar previsto pelas portarias e documentos e as práticas das realidades locais de um município fluminense. No referido estudo, profissionais da eSF elencaram como motivos desse hiato o perfil de saúde agravado dos usuários e o consequente prejuízo das medidas de prevenção; o movimento cíclico chamado por eles de "apagar incêndios", que atuava na resolução das urgências, muitas vezes sob ordens judiciais, atrapalhando a continuidade das ações planejadas; e, ainda, um problema relacionado à gestão, com pouco investimento para alcance de maior qualidade 
dos programas de prevenção. Além disso, os entrevistados indicaram a alta rotatividade dos profissionais das equipes como fator que dificultava a articulação, planejamento e extensão das ações de cuidado.

Os resultados do estudo de Valadão, Lins e Carvalho (2019) corroboram essas dificuldades ao mostrarem que profissionais das eSF de um município da região metropolitana de Salvador, entrevistados em relação à operacionalização do cuidado, evidenciaram aspectos críticos, como demandas crescentes relativas às doenças crônicas, que geram sobrecarga de trabalho e restringem a realização de atividades educativas e de promoção à saúde; as barreiras na articulação com os outros níveis de atenção; e uma formação acadêmica ainda aquém das mudanças curriculares necessárias.

É importante ressaltar que os conceitos de integralidade e de longitudinalidade do cuidado, centrais na PNAB, foram aspectos fundamentais para a construção do projeto cujas ações são aqui relatadas, tendo em vista o alcance pretendido de seus objetivos e as estratégias de atuação direta da equipe de saúde envolvida. A integralidade constitui um dos princípios filosóficos e recebe lugar de destaque na referida política, implicando na cobertura de cuidado amplo às necessidades reais da população a partir do seu reconhecimento e mapeamento. A integralidade é assim definida pela própria normativa: “[...] conjunto de serviços executados pela equipe de saúde que atendam às necessidades da população adscrita nos campos do cuidado, da promoção e manutenção da saúde, da prevenção de doenças e agravos". Além disso, "inclui a responsabilização pela oferta de serviços em outros pontos de atenção à saúde e o reconhecimento adequado das necessidades biológicas, psicológicas, ambientais e sociais causadoras das doenças" (BRASIL, 2017, p.6).

A longitudinalidade do cuidado, por sua vez, constitui uma diretriz importante para nortear o trabalho em saúde e corresponde à continuidade da relação de cuidado ao longo do tempo, respeitando os vínculos construídos e a responsabilização entre profissionais e usuários, de modo a garantir o acompanhamento dos efeitos das intervenções realizadas (BRASIL, 2017). Dentre os benefícios estimados do cuidado longitudinal, espera-se um reconhecimento mais apurado das necessidades dos usuários e uma maior satisfação destes 
com o sistema de saúde, favorecendo as ações de prevenção e de promoção da saúde (STARFIELD, 2002).

Nessa direção, as finalidades delineadas para este estudo dialogam também com o objetivo geral da PNPS (BRASIL, 2006; 2014), no que se refere à redução de vulnerabilidades e riscos à saúde, além de ter correspondência com seus objetivos específicos, sobretudo a valorização e otimização do uso de espaços públicos de convivência e de produção de saúde para o desenvolvimento das ações de promoção da saúde; a prevenção de fatores determinantes e/ou condicionantes de doenças e agravos à saúde; e a estimulação para que sejam adotados modos de viver não-violentos, desenvolvendo uma cultura de paz no país.

A promoção da saúde ganha força na $A B$, especialmente nas eSF, pela potencial proximidade dos profissionais de saúde com os usuários e pelo trabalho territorial. As equipes possuem ferramentas e contam com agentes de saúde que auxiliam no mapeamento das condições de vida da população, condição primeira para qualquer intervenção (PNAB, 2017). Assim, se as propostas da PNAB e da PNPS consistem em atuar integralmente com foco na saúde ampliada, entende-se que por meio delas se torna possível afetar positivamente pessoas em diferentes condições de vulnerabilidade.

\section{VULNERABILIDADES RELACIONADAS À SAÚDE DE ADOLESCENTES E POTENCIALIDADES DA PROMOÇÃO DA SAÚDE EM AMBIENTE ESCOLAR}

O Brasil sofre de um desmonte do recém e inacabado estado de bem-estar social (MINAYO, 2006). O Rio de Janeiro destaca-se como um dos estados mais afetados pela crise política-econômica-social que abala as políticas públicas do país e reduz as condições dignas de vida da população (CAMPANATI, 2018). Neste contexto, as instituições políticas e de gestão encontram-se estigmatizadas pela prática recorrente da corrupção e observa-se um cenário de desesperança social. Reconhece-se, assim instituída, a violência estrutural que alija direitos, oportunidades e esperanças. Este tipo de violência diz respeito às práticas dos sistemas econômicos, políticos e culturais que afetam as condições de vida da população e 
negligenciam direitos. Segundo Minayo (1994, p. 2), “conduzem à opressão de grupos, classes, nações e indivíduos, aos quais são negadas conquistas da sociedade, tornando-os mais vulneráveis que outros ao sofrimento e à morte".

Desse modo, a violência estrutural é o campo naturalizado das negligências concretas e simbólicas, das práticas de discriminação e preconceito e do apartheid social (MINAYO, 2006). No entanto, Minayo, Souza, Silva e Assis (2018) sinalizam que a temática das violências ainda busca se consolidar como eixo de atenção no Sistema Único de Saúde (SUS). Em muitos casos, demandas dessa esfera ficam reprimidas, de modo que não se apresentam espontaneamente nas unidades de saúde e, ainda que isso ocorra, recebem pouca atenção dos profissionais envolvidos. É importante sinalizar o potencial, na $\mathrm{AB}$, para se agir no próprio território da violência mediante o envolvimento de diversos sujeitos em situações de vulnerabilidade e risco (BARBIANI, 2016).

No que diz respeito às vulnerabilidades, Silva, Mello, Mello, Ferriani, Sampaio e Oliveira (2014) indicam que estas podem ser analisadas com base em três eixos, a saber: o individual, o social e o programático. Para os autores, o viés individual corresponde ao próprio modo de vida das pessoas, incluindo valores e crenças. Sobre o viés social, eles apontam os aspectos que possibilitam entender comportamentos e práticas relacionados à exposição a agravos e adoecimentos, como acesso à educação, liberdade de pensamento e expressão, cidadania, estigma e discriminação. O enfoque programático aborda como as instituições atuam diante dos contextos desfavoráveis da vulnerabilidade, ou seja, interroga-se como tais entes a favorecem ou a reduzem com suas práticas e discursos.

Neste estudo, a atenção volta-se para as vulnerabilidades individuais associadas às sociais, a fim de salientar a complexidade e a formação social dos processos de saúde-doença, com enfoque mais específico sobre prejuízos de cunho subjetivo relacionados às perspectivas e condições de vida menos positivas. Porém, é importante lembrar que as condições de trabalho e de organização da equipe do projeto configuram-se como elementos da ordem programática (ou institucional) das vulnerabilidades, o que pode revelar potencialidades ou entraves ao longo das intervenções. 
O trabalho de prevenção de agravos e de promoção da saúde no contexto das vulnerabilidades prescinde de mudanças paradigmáticas no que concerne à forma da atenção ofertada. Conforme Ayres (2003) aponta, no modelo das vulnerabilidades, o público-alvo são populações suscetíveis e o objetivo é promover ações intersetoriais que possam favorecer capacidades de resposta com vistas a alcançar a transformação de contextos e de relações. Esse modelo contrasta com aqueles cujo foco é a prevenção tradicional, que têm como objetivo alertar indivíduos expostos a certas situações, tidas como de risco, e obter mudanças de comportamento.

Por meio de mapeamento do território, no presente estudo, foram verificadas condições de vulnerabilidade a que estavam expostos usuários em diferentes momentos do ciclo de vida, incluindo urgências relativas aos adolescentes, aqui compreendidos, conforme a Organização Mundial de Saúde (OMS, 1986), como pessoas que vivenciam a segunda década de vida, dos 10 aos 19 anos. Parte desse grupo etário tem sido prejudicado sistematicamente por muitas negligências, como uma educação de baixa qualidade e restritas oportunidades de preparação para o mercado de trabalho formal.

As crianças e os adolescentes constituem sujeitos de direitos e devem ter garantidas sua proteção integral e pleno desenvolvimento (BRASIL, 1990). No Brasil, desde o final da década de 1980, a população infantojuvenil conta com um sistema de garantia de direitos, sendo previstas intervenções sempre quando houver ameaça ou violação dos seus direitos sociais básicos, como direito à vida, à saúde, à convivência comunitária, à liberdade, ao respeito e à dignidade (BARBIANI, 2016). As violações de direitos essenciais à manutenção da vida dizem respeito, por exemplo, ao acometimento por doenças, incluindo aquelas decorrentes de habitação e saneamento básico precários; as infecções sexualmente transmissíveis; e a mortalidade devido a causas externas, como homicídios. Dentre as principais formas de violação ao direito à liberdade, ao respeito e à dignidade estão o aliciamento para atividades ilícitas ou impróprias, o abuso e exploração sexual e a violência doméstica (DOMINGUES; PEREIRA; OLIVEIRA; ABRANTES; CARDOSO; MOURA, 2018). 


\section{Revista \\ Debates Insubmissos}

No intuito de conhecer e atuar sobre as perspectivas de vida do público infantojuvenil é preciso reafirmar o compromisso da saúde como uma força potencial para a garantia de direitos desse segmento da população. Como expresso no Estatuto da Criança e do Adolescente

A criança e o adolescente gozam de todos os direitos fundamentais inerentes à pessoa [....], sem prejuízo da proteção integral de que trata esta Lei, assegurando-selhes, por lei ou por outros meios, todas as oportunidades e facilidades, a fim de lhes facultar o desenvolvimento físico, mental, moral, espiritual e social, em condições de liberdade e de dignidade (ECA, Art. $3^{\circ}, 1990$ ).

Silva et al. (2014) ressaltam que as vulnerabilidades exigem um olhar extenso e aprofundado que deve incluir as perspectivas dos próprios adolescentes. Imbuídos desse propósito, os referidos pesquisadores entrevistaram 17 adolescentes de duas escolas de educação fundamental de um município do interior do estado de São Paulo, visando analisar como estes percebiam tanto a vulnerabilidade quanto a saúde dos jovens. Os participantes mostraram conceber uma interação entre a predisposição individual (por exemplo, falta de conhecimento em relação à vida sexual saudável, de responsabilidade e de autocuidado) e questões relacionadas à estrutura social (por exemplo, condições materiais de vida, comunidades seguras), apontando ainda a necessidade de ações governamentais efetivas para a emancipação da vida, de melhor educação e de mais fácil acesso aos serviços de saúde. Isso evidenciou uma concepção de vulnerabilidade ancorada nas lógicas tanto individual e social como programática.

Partindo dessa compreensão, o foco das ações realizadas dirigiu-se aos aspectos do desenvolvimento social e mental dos jovens e a proposta de intervenção ganhou corpo com uma aproximação das temáticas da saúde mental e de projetos de vida mediante a abertura de espaços de troca e diálogo, com a facilitação e o fomento a reflexões, incluindo vírgulas e intervalos importantes em discursos paralisados e paralisantes.

Nessa direção, Prates, Prates, Silva, Ferreira, Araújo e Andrade (2019) defendem as oficinas educativas junto a adolescentes em situação de vulnerabilidade social como uma metodologia ativa e um espaço dialógico de trabalho coletivo que deve partir do levantamento de suas necessidades e anseios e buscar emancipação e transformação por meio da ação- 
reflexão-ação. As temáticas a serem abordadas podem ser diversas, incluindo desenvolvimento pessoal, empoderamento, cidadania, construção de projeto de vida e prevenção da violência. Mas, quaisquer que sejam elas, devem ser trabalhadas de modo dinâmico, acolhedor, lúdico, dialógico e problematizador para que as oficinas possam se constituir como um dispositivo potente de educação em saúde e de promoção da cultura de paz, colaborando para romper com uma relação vertical entre profissional da saúde e usuários e facilitar a expressão individual e plural das necessidades, expectativas e circunstâncias de vida que influenciam no processo saúde-doença-cuidado.

Orientando-se pelas concepções teóricas e lógicas de cuidado aqui defendidas, outros espaços de convivência além da saúde ganham peso e importância para as ações de promoção de saúde e funcionam como terrenos férteis para os objetivos da atenção integral à saúde. Adota-se o conceito de intersetorialidade, articulando-o aos trabalhos, com integração de saberes e ações. A escola destaca-se nesse âmbito, sendo avaliada - nacional e internacionalmente - como espaço potencial de cuidado (CASEMIRO; DA FONSECA; SECCO, 2014; COSTA, 2014). De fato, a escola, como instituição na qual os alunos formam hábitos e valores e vivenciam processos importantes de socialização, constitui um espaço privilegiado para ações promotoras e cuidadoras da saúde, para além da educação formal (GOMES, HORTA, 2010).

No ambiente escolar, a relação dos adolescentes com o espaço e pessoas tende a ser mais fluida e profunda, o que facilita a expressão e/ou a leitura de diferentes questões (NJAINE; MINAYO, 2003). Isso evidencia o potencial da escola para atuar como um local apto à promoção e ao fortalecimento de políticas de saúde voltadas aos jovens. Entretanto, a parceria saúde-educação necessita se estabelecer com vínculos fortes e contínuos, que devem ir além de ações pontuais ou isoladas. Como constata uma revisão bibliográfica realizada por Casemiro et al. (2014, p. 5) sobre a saúde escolar na América Latina, "ainda são realizadas ações de saúde escolar em que a escola é apenas cenário de pesquisa e objeto de iniciativas centradas na doença. Os dados não retornam aos sujeitos ou à realidade pesquisada”. 
Conforme Gomes e Horta (2010), o aprimoramento da atuação conjunta dos setores de educação e de saúde com vistas ao planejamento e à implementação de ações integrais cuidadoras da população infantojuvenil, sobretudo em áreas de vulnerabilidade, pode contribuir sobremaneira para um bom desenvolvimento das ações de saúde no ambiente escolar, favorecendo ganhos e inovações nas estratégias de promoção de saúde e na continuidade de experiências bem-sucedidas. Podem ainda propiciar resultados positivos para os jovens, com incentivo ao autocuidado, incremento da qualidade de vida e construção de sujeitos-adolescentes, amenizando as vulnerabilidades e desenvolvendo suas potencialidades.

Diante do exposto, realizou-se um trabalho de natureza educativa com adolescentes no contexto de uma escola pública de um município fluminense, tendo por objetivos: (a) recuperar as práticas de prevenção de agravos e promoção da saúde da equipe multiprofissional em questão; (b) abrir canais de comunicação e vinculação com a população infantojuvenil do território; e (c) atingir positivamente a perspectiva de vida de adolescentes de um território marcado por vulnerabilidade social.

\section{MÉTODO}

O projeto foi desenvolvido por profissionais vinculadas a uma Unidade Básica de Saúde (UBS) de um município de pequeno porte do Rio de Janeiro, com população de 134 mil habitantes segundo o censo do Instituto Brasileiro de Geografia e Estatística de 2020 (IBGE, 2020). O referido município situa-se no contexto urbano do estado, próximo às áreas periféricas da cidade do Rio de Janeiro e das cidades da Baixada Fluminense, marcadas pela desigualdade social e altos índices de violência (Instituto de Segurança Pública, 2018). A rede de saúde da cidade possuía uma boa cobertura de equipamentos, sobretudo os de AB, ainda que tivesse equipes incompletas. Em relação à educação, o Instituto Nacional de Estudos e Pesquisas Educacionais Anísio Teixeira indica que o Índice de Desenvolvimento da Atenção Básica (IDEB) do município não havia atingido as metas previstas para a $4^{\mathrm{a}}$ série ao $9^{\circ}$ ano no último censo escolar, de 2017. 
Primeiramente, foi realizado um diagnóstico situacional das necessidades de saúde do território. Teixeira (2010, p. 21) defende que "a ideologia e o conhecimento da situação de saúde são elementos básicos para a formação da imagem-objetivo, os quais permitem identificar as áreas problema que devem ser consideradas". O território foi relativo a um bairro localizado próximo ao centro da cidade, sem equipamentos públicos ou privados de lazer e/ou esporte. De âmbito público, havia a UBS, com equipes mistas, um centro de referência da assistência social (CRAS), o programa de vigilância voltado às ações em relação a infecções sexualmente transmissíveis e AIDS e uma escola estadual municipalizada, que ofertava o ensino fundamental. Destacava-se ali a presença de uma organização não governamental, associação conveniada a uma grande siderúrgica da região, que disponibilizava aulas de música e de artes para adolescentes da cidade.

O mapeamento foi realizado mediante visitas domiciliares da psicóloga e da fisioterapeuta, acompanhadas por ACS. A observação e o registro das vulnerabilidades também se deram pela circulação das profissionais no bairro e por questões trazidas pela população por ocasião da coleta de dados de uma pesquisa de mestrado sobre os efeitos da violência urbana (CAMPANATI, 2018). Nessa investigação, observou-se a preocupação das famílias com as crianças e os adolescentes do bairro. Os entrevistados sinalizaram baixa autoestima e falta de perspectivas entre crianças e adolescentes, revelando haver uma reprodução da violência social e simbólica que eles próprios também tinham vivenciado.

Neste cenário territorial, destacava-se a violência urbana (MINAYO, 2006; MISSE, 2006), marcada pela presença do tráfico armado na região, episódios recorrentes de tiroteio e cerceamento do ir e vir da população e equipes de saúde. Tendo em vista dados levantados por Campanati (2018), mediante entrevistas com profissionais e usuários, a violência simbólica (BOURDIEU, 1989) manifestava-se por meio do estigma relacionado ao bairro, reconhecido como feio e perigoso, com eco na percepção de desvalorização da gestão do município para com a população e desta para consigo mesma. A violência estrutural, também chamada de social, foi trazida em relatos do estudo citado acima, expressa pelas vivências de negligência para com os direitos daquela população, incluindo crianças sem a grade completa 
de aulas ou faltosas por episódios de tiroteio e/ou medo, bem como equipes de saúde incompletas ou sem recursos para atuarem diante das gravidades percebidas. Desses importantes determinantes sociais da saúde, avaliou-se que atuar junto a crianças e jovens seria o principal objetivo.

Optou-se por atuar em uma escola pública estadual municipalizada, com os dois grupos iniciais do $2^{\circ}$ segmento da educação básica, que correspondem aos $6^{\circ}$ e $7^{\circ}$ anos e incluem pré-adolescentes e adolescentes, envolvendo alunos dos 11 até os 15 anos. Esta escolha foi justificada por este público se encontrar em uma fase importante da formação da própria identidade e de seus valores, configurando-se, portanto, como um momento importante de reconhecimento de si e de delineamento de projetos futuros (HURTADO, 2012).

Com a intenção de apresentar a equipe e o projeto de maneira viva e dinâmica, percorreu-se por todas as turmas antes do início das ações, explicando os objetivos e realizando um convite mais afetivo. Cumprindo as exigências éticas para o trabalho com crianças e adolescentes (BRASIL, 1990), todas as famílias foram informadas sobre a intervenção e convidadas para uma reunião de apresentação dos seus objetivos iniciais, com abertura para sugestões e dúvidas.

\subsection{Pontos de partida: atores e contexto da prática}

A ideia do projeto surgiu da interlocução entre uma profissional da psicologia e outra da fisioterapia, com inclusão de ACS nessas ações, em esquema de rodízio, de forma que todas elas pudessem se familiarizar com a proposta de intervenção. Como trabalho subjetivo que supõe identificação e preferências, ao longo do projeto algumas das ACS se aproximaram mais e uma delas tornou-se membro efetivo, tendo sua agenda compromissada com os encontros realizados na escola.

Para contextualizar a experiência em questão, foi necessário um esforço de sistematização que possibilitasse compreender suas origens e alcances pretendidos. As ações traçadas não surgiram de um dia para o outro e envolveram angústias e inquietações. No 


\section{Revista (O) \\ Debates Insubmissos}

entanto, os elementos imprevistos mobilizaram a criação de novas formas de atuação, demonstrando a possibilidade de iniciativa e de autonomia diante da agenda de trabalho.

As profissionais de nível superior à frente do projeto não atuavam como membros obrigatórios da equipe mínima na eSF, por suas áreas de formação estarem configuradas, segundo a PNAB (BRASIL, 2017), como especialidades, e, por isso, exerciam uma carga horária diferente do restante da equipe. Esse lugar provisório e menos rotineiro trazia certas possibilidades. Uma delas era a fluência do escopo, com extensão das ações da equipe que ali atuava todos os dias da semana, desenhando ações cabíveis e mais potentes para este enquadre. Desejava-se ultrapassar as ações estanques, mas que traziam dilemas éticos importantes, dado os muitos tipos de adoecimento já instalados na região.

Um elemento crucial que possibilitou o avanço do trabalho foi o mal-estar da equipe diante das cronicidades e violações de direitos encontradas no território. Frente a esse reconhecimento, as profissionais buscaram localizar espaços nos quais suas ações pudessem fazer um movimento de resistência à reprodução dos fenômenos de negligência para com as demandas daquela população. Nesta busca de lugares de potência, a equipe se valeu do mapeamento do território a fim de levantar questões de baixa à média complexidade, que pudessem ser abordadas antes da gravidade ser instalada. A PNPS defende que "a partir da visibilidade aos fatores que colocam a saúde da população em risco e às diferenças entre necessidades, territórios e culturas presentes no nosso País, sejam construídos transversalmente mecanismos que reduzam as situações de vulnerabilidade" (BRASIL, 2006, p.12).

Nesse percurso, avaliamos ainda a necessidade de outras ideias e ações para o território e, corroborando um dos princípios da $\mathrm{AB}$, seguiu-se pela intersetorialidade, posto que afetar os determinantes sociais da saúde não é papel restrito da saúde. Realizamos a aproximação e um acolhimento com e pela escola, sendo todo o processo marcado por abertura e diálogo. A escola mostrou-se ávida por cuidados diante de uma equipe interessada em seus movimentos. 
Como apontado pela PNPS, a ampliação do comprometimento e da corresponsabilidade entre trabalhadores da saúde, usuários e território em que se localizam altera os modos de atenção e de gestão dos serviços de saúde, uma vez que a produção de saúde se torna indissociável da produção de subjetividades mais ativas, críticas, envolvidas e solidárias e, simultaneamente, exige a mobilização de recursos políticos, humanos e financeiros que extrapolam o âmbito da saúde. Assim, coloca-se ao setor saúde o desafio de construir a intersetorialidade (BRASIL, 2006, p.13).

O projeto passou a integrar a agenda de trabalho da equipe, incluindo reuniões de feedback e planejamento das ações com a orientadora e a diretora da escola, bem como reuniões da própria equipe com a mesma finalidade.

\subsection{As estratégias de intervenção na escola}

O projeto abrangeu seis turmas no total, sendo três turmas do $6^{\mathrm{a}}$ ano e três turmas do $7^{\circ}$ ano do ensino fundamental. Os encontros tiveram frequência semanal, ao longo de um período de seis meses de duração, sendo um mês dedicado a cada turma, com quatro reuniões com cada uma delas. Esses eventos duravam duas horas e eram realizados nos chamados "tempos vagos" das grades curriculares, o que revelou amplo espaço de ausências naqueles projetos pedagógicos. Adotou-se o método da Roda de Conversa, valorizada por Freire (2007), por compreendê-la como espaço de promoção de trocas, de relações mais horizontalizadas e de fomento à voz dos grupos que a compõem. Inicialmente, buscou-se abordar o tema projeto de vida pelo conceito de projeto vital, com base na Psicologia Positiva que, segundo Araújo (2007), caracteriza-se por estudar os fatores que promovem o desenvolvimento dos sujeitos e suas forças psicológicas. Hurtado (2012) aponta que tais projetos dão sentido à vida das pessoas, pois organizam pensamentos e ações, estando associados aos sistemas de valores daqueles sujeitos. Nas reuniões foram inseridas as temáticas da saúde em sua forma ampliada como disparadora das conversas e trocas.

Porém, no decorrer dos encontros, observou-se a necessidade de trabalhar aspectos mais fundamentais da saúde, aproximando a temática do projeto de vida com maior entendimento e mutualidade, no sentido de tornar as discussões mais acessíveis e, a partir 
disso, favorecer mais trocas e uma participação ativa, garantindo o caráter dialógico que se desejava nas reuniões. Procurou-se não reproduzir a prática das palestras, com formato de transmissão de informação unilateral, enquadre já conhecido e esperado pelos grupos de adolescentes. Desejava-se levar informações pertinentes aos encontros, mas de forma emancipatória e libertadora, que incluísse os saberes dos sujeitos ali ativos e fizesse sentido nos seus mundos de significado, favorecendo a crítica e a autonomia em suas vidas (FREIRE, 2007).

Para essa aproximação e quebra do esquema já esperado pelos jovens, foram utilizadas também dinâmicas de grupo que exploravam, de maneira lúdica, compreensões sobre saúde ampliada e, mais especificamente, sobre saúde mental. Orientados pelas dinâmicas, os temas passaram também a ser trazidos por eles, o que foi acolhido, com as reorganizações necessárias da equipe, sendo suas sugestões incluídas nos encontros seguintes. Na abordagem dos sonhos e projetos de vida, abriu-se espaços subjetivos, interrogando os estigmas e as vivências de forma cuidadosa, de modo a problematizar as questões sociais e não cair na armadilha de psicologizar todas as dificuldades e barreiras encontradas por este público em seus desejos e trajetórias.

As principais dinâmicas realizadas foram as seguintes:

- Estrela do Tempo, em que se utilizou três pontas de uma estrela como orientação temporal, sendo que cada uma das pontas representava cinco anos de vida à frente. A finalidade foi trabalhar projetos de vida dos estudantes nas suas relações com o tempo.

- Notas da minha Saúde, que buscou promover o debate sobre a saúde ampliada e estimular relatos dos participantes sobre a temática a partir de suas próprias perspectivas. No intuito de ampliar a visão de saúde para além da concepção biológica, pediu-se a eles que avaliassem também a própria saúde mental, bem como a saúde de suas famílias e do seu bairro. Esta atividade permitiu protagonismo aos estudantes, ao facilitar a eles um espaço de reflexão e de valorização de suas falas e experiências.

- Cartão-assunto, que objetivou dar atenção individualizada ou de menos exposição aos alunos para mostrarem, espontaneamente, os assuntos que gostariam que fossem 
abordados no trabalho com eles. Esta iniciativa ocorreu após o reconhecimento, por parte da equipe, da necessidade de um espaço mais reservado às sugestões ou pedidos de acolhimento dos estudantes, já que alguns deles procuravam os profissionais na escola para pedirem orientações e/ou inclusão de temáticas que denotavam certa vergonha, como a questão do excesso de peso. Essa dinâmica destacou a relevância do assunto "aparência e limpeza da escola", apontado em mais de uma turma e cujo debate se desdobrou em uma ação de revitalização da escola. A equipe de saúde articulou com a equipe escolar a pintura do muro da biblioteca e uma enquete decidiu qual desenho seria a arte do muro, sendo que a mascote da copa do mundo ganhou a votação.

\section{RESULTADOS E ANÁLISE}

Os primeiros encontros trouxeram a percepção de que os grupos estavam preparados para receberem informações, mas não para participarem ativamente do projeto. Notou-se a surpresa dos alunos quanto ao protagonismo ofertado, tanto no sentido de se expressarem, quanto poderem escolher os temas que seriam trabalhados. Observou-se a surpresa destes ao escutarem a própria voz, ao reconhecerem a opinião exposta, o que também trazia timidez, pois as facilitadoras valorizavam quaisquer falas, piadas, argumentos; e isso parecia gerar certo espanto nos estudantes. No início, a equipe do projeto foi confundida com dentistas ou "pessoas que dão injeção", possivelmente profissionais de saúde mais presentes nas escolas e, por isso, mais reconhecidos pelos alunos, evidenciando um modelo de atuação da área da saúde ainda prevalente na escola, voltado para ações pontuais, sem vinculação e/ou continuidade. Avaliou-se que tal percepção dos adolescentes se deu em função das ações do Programa Saúde na Escola (PSE) (Brasil, 2007), sobre o qual Lopes, Nogueira e Rocha (2018) destacam, em um trabalho de revisão integrativa, que muitas atividades preservam uma perspectiva fragmentada do cuidado, divididas por assunto estanques, tais como saúde ocular, nutricional, sexual e reprodutiva.

Esta vivência trouxe o desafio de orientar e fomentar as falas sem abrir mão do espaço de troca e interlocução, dificuldade salientada por Freire (1983, p.43), quando sinaliza que 
nessas experiências não basta "dizer-se descomprometidamente dialógico; é [preciso] vivenciar o diálogo. Ser dialógico é não invadir, é não manipular, é não organizar. Ser dialógico é empenhar-se na transformação constante da realidade".

Sustentando este fomento ao longo das reuniões, as rodas de conversa foram adquirindo um caráter emancipatório. Falava-se de vida e, assim, de uma saúde melhor, com mais nuances, cores e maior reconhecimento pessoal na temática, agora mais psicossocial e menos estritamente biológica. Com o decorrer do trabalho, observou-se o reconhecimento da importância da atividade pelos adolescentes. Houve casos em que alguns deles apresentavam integrantes da equipe de saúde a suas famílias, ao avistarem estes na rua, ou buscavam alertar e/ou lembrar à equipe da escola de que era "dia de encontro". Inclusive questionavam acerca de datas das próximas reuniões e pediam a continuidade dos encontros com cada turma.

Destaca-se que, inicialmente, a compreensão da escola sobre os objetivos do projeto foi interpretada de maneira diferente do pretendido. Na apresentação, a direção escolar pressupôs que o trabalho que a equipe ofertaria seria o tratamento psicológico de cuidar das rotuladas "crianças-problema". Essa demanda foi ouvida, analisada e o que se destacou dessa visão foram os adolescentes recorrentemente repetentes, que, segundo a direção da escola, atrapalhavam o funcionamento das turmas, e as crianças e adolescentes com transtornos mentais e/ou comportamentais, que necessitavam de atenção especializada. Para além das questões com este público, houve também o pedido de ajuda da escola no sentido de aproximação das famílias, que, conforme a instituição, estavam distanciadas da rotina escolar.

Combinou-se que a equipe estaria disponível na UBS para acolhimentos, tratamentos e encaminhamentos necessários às demandas de crianças e adolescentes que necessitavam de atenção especializada e que se buscaria, com a orientação pedagógica, auxiliar os projetos de maior atenção aos adolescentes com recorrentes repetições, reiterando a preocupação não apenas com o andamento das turmas em que eles estavam inseridos, mas também com suas trajetórias. Nesta escola, foi encontrado trabalho e terreno. Em vez de negar essa atenção às “crianças-problemas", buscou-se entender os problemas dessas crianças, da comunidade 
escolar e das famílias. Uma lição importante foi a de acolher a escola como ela estava, o que significava ouvir o que ela queria e sentia.

Em espaços de troca e/ou de reuniões intersetoriais, notava-se discursos estigmatizantes dos profissionais sobre a região e sua população e acredita-se que tais narrativas atuavam no fortalecimento destas negligências, posto que naturalizavam os quadros de pouco investimento e atenção para com a população, eliminando a historicidade dessa construção. Vale ressaltar que a característica marcante dos estigmas é delimitar destinos e encerrar possibilidades, dando o discurso por finalizado (BOURDIEU, 1989).

Esta foi a situação de um adolescente que sentia falta da mãe e cuidava do irmão mais novo devido ela estar em uma penitenciária e o pai mostrar instabilidade relacionada ao uso abusivo de álcool e outras drogas. Mediante esse acolhimento, foi reconhecido um suporte que ele recebia dos jovens envolvidos com o tráfico da região e que lhe rendia um estigma na sala de aula, sendo alvo de indiretas que sugeriam seu envolvimento em atividades ilícitas. $\mathrm{O}$ próprio adolescente expressava incômodo com os auxílios que recebia e lamentava precisar deles, revelando um medo de futuras dívidas com aquele grupo. Respeitando a confiança adquirida e preocupando-nos em dar algum encaminhamento às questões, comunicou-se à direção escolar a configuração apontada pelo jovem em relação ao seu quadro familiar, de forma que fosse possível atuar conjuntamente na convocação do seu pai e no entendimento da situação da sua mãe.

A vinculação da escola, sobretudo da direção e da orientação pedagógica, com a equipe multiprofissional estabeleceu uma ponte importante para a integralidade do cuidado a algumas crianças. Esse foi o caso, por exemplo, de um aluno cuja mãe enfrentava intenso sofrimento mental, o que vinha acarretando um quadro de desnutrição na criança e gerando riscos de perda provisória de guarda parental dadas as denúncias da comunidade ao Conselho Tutelar. Essas situações eram trazidas pessoalmente ou por telefone por representantes da escola e os trabalhos passavam a caminhar juntos, com mais trocas e possibilidades. Ainda que essas ações ultrapassassem o escopo de ações do projeto, elas faziam parte da agenda de 


\section{Revista
Debates Insubmissos}

trabalho e a escola atuava como um importante agente de parceria, posto que nem sempre essas situações eram observadas na UBS ou nos domicílios.

Nos encontros, a primeira dinâmica realizada - A Estrela do Tempo - trouxe surpresa quanto à dificuldade de abstração por parte das turmas do $6^{\circ}$ ano. Isso mostrou a importância de se refletir sobre impasses concretos da falta de perspectiva de vida e/ou baixa autoestima presentes entre os alunos. Constatou-se pré-adolescentes e adolescentes com dificuldade de dimensionar o futuro em períodos de tempo de cinco e dez anos à frente. Nessa atividade, destacou-se uma dificuldade maior nos adolescentes mais velhos, conhecidos como os "repetentes". Nesses casos, observou-se que os entraves vinham de um ineditismo nas perguntas sobre eles e seus projetos e/ou de uma baixa estimulação quanto à reflexão e ao reconhecimento de si e do que os compunham, para além das repetições de série. Considerouse que o estigma "repetentes" também tenha pesado nessa trajetória, como se esse termo designasse alguém para quem o tempo já passou.

Nas turmas do $6^{\circ}$ ano, sobressaiu-se ainda o fascínio dos alunos em poder falar das projeções associadas aos relacionamentos afetivos-sexuais. Foi possível presenciar reações exacerbadas em relação aos planos de namoro e de início da atividade sexual. Atitudes como risos e piadas ou indicativos de desconcertos e timidez denunciavam que o assunto tinha status de tabu e que uma mediação seria importante ali. Procurou-se não reprimir a temática, mas tratá-la com seriedade e leveza. Com uso da dinâmica da estrela do tempo, verificou-se que a maior parte desses desejos apareciam na segunda ponta da estrela, ou seja, em relação aos planos para os próximos dez anos. Notou-se maior dificuldade em falar de desejos e projetos para os cinco anos à frente, em média até os seus 18 anos, como se essas aspirações só estivessem espaço na vida adulta. Assim, foram problematizadas as recriminações que iam surgindo entre eles. Ouviam-se risos sobre aqueles que assumiam o que escreveram e, com as intervenções, os ânimos se acalmavam. Percebeu-se também um ineditismo quanto à discussão do assunto e a própria turma apontava que tais temáticas eram proibidas em casa, seja pela ausência de abertura da família, seja pela ideia de pecado. As turmas do $7^{\circ}$ ano 


\section{Revista
Debates Insubmissos}

tiveram mais facilidade na dinâmica, trazendo projeções ora mais concretas, ora mais idealizadas.

$\mathrm{Na}$ ação de revitalização de um espaço da escola, a pintura foi realizada na época da copa do mundo de futebol. Porém, neste momento, a seleção brasileira já havia sido eliminada, o que trouxe desânimo e certo arrependimento de terem escolhido a mascote do evento para a pintura, como se dissessem "não adianta mais torcer". Diante dessas falas, trabalhou-se a continuidade de ser torcedor, nas vitórias e derrotas, a importância da finalização de um trabalho organizado por todos desde o início e os sentimentos de frustração e tristeza como elementos que devem ser acolhidos. O professor de português do $7^{\circ}$ ano aderiu à atividade e participou da pintura, auxiliando os alunos com orientações. Essa atividade, por ter sido realizada em um espaço amplo e externo, trouxe maior apreensão em relação ao enquadre e manejo com os adolescentes, que dispersavam mais rapidamente que na sala de aula. Ao mesmo tempo, essa fluidez do espaço dava lugar a um maior relaxamento e a uma abertura dos alunos para falarem ao seu modo, com seus movimentos extensos e difíceis de acompanhar.

Durante esse acompanhamento, foram identificadas outras tensões que permeavam o ambiente escolar: as "pichações do tráfico" nos outros muros, que eles gostariam de apagar; as frases bíblicas que gostariam de usar com o desenho escolhido; a preocupação com o termo "canarinho pistola", que parecia remeter à violência armada da região; e os inícios de "brigas" (contatos corporais ora mais intensos, ora mais suaves) dentre aqueles que tinham maior dificuldade de concentração na pintura. Aos poucos, essas "brigas" ganharam lugar de teatro, estimulando vídeos de cenas de conflitos que simulavam novelas mexicanas, as quais diziam assistir com as mães e avós.

Os resultados apontaram avanços nas seguintes vertentes: a) efeitos diretos à população-alvo do projeto e b) efeitos indiretos, vivenciados pela eSF durante a realização do projeto. O impacto considerado como o mais direto foi a construção de vínculos com os préadolescentes e adolescentes, quando se percebeu o referenciamento destes à equipe como agentes de cuidado e fontes de confiança, inclusive para além do escopo das ações na escola, 
o que se manifestou através de pedidos de atendimentos psicológicos individuais e de conversas mais longas com a equipe pela justificativa de não encontrarem esse espaço em suas famílias, seja por motivos religiosos ou por questões de maior vulnerabilidade.

O perfil agravado dos usuários da $\mathrm{AB}$ urge e atravessa o cuidado primário. Conclui-se que é preciso avançar em passos ágeis e seguros. É preciso ir ao encontro das necessidades e demandas das crianças e provocar-lhes reflexões que fortaleçam seu potencial, não no sentido da racionalização do tempo e no gerenciamento (empresarial) dos projetos de vida, mas no sentido da cidadania crítica e afetiva, capaz de vivenciar e pensar a própria experiência, reorientando percursos e destinos (NAVARRO, 2019). Para tanto, faz-se necessária a continuidade dos estudos e trabalhos que versem sobre a perspectiva dos próprios adolescentes, ampliando assim o campo de análise das vulnerabilidades e das ações em saúde (SILVA et al, 2014).

Os efeitos indiretos do projeto apontaram para uma prática profissional mais planejada, refletida e realizada com alegria, engajamento e empoderamento pelas ACS; ampliação das ações de promoção da saúde na agenda de trabalho da equipe, com parcerias para além dos setores inicialmente envolvidos; menor isolamento da Psicologia nas ações da equipe, com fortalecimento dos debates sobre a saúde mental no nível da atenção primária, além de maior vinculação entre a escola e a equipe de saúde.

\section{CONSIDERAÇÕES FINAIS}

Iniciou-se o trabalho interrogando o alcance de ações de promoção de saúde mental na $\mathrm{AB}$ e encontrou-se, neste projeto, um exemplo sólido de como é possível e importante atuar promovendo autonomia, pertencimento e autoestima, sem se limitar a reparar danos, que muitas vezes se tornam transtornos pela reprodução e pelo enraizamento na população. Neste sentido, defende-se que a Psicologia na $\mathrm{AB}$ pode (e deve) servir mais que ponto de apoio, ela pode propiciar fazeres conjuntos com potencial para fortalecer a interdisciplinaridade e caminhar rumo à transdisciplinaridade. 
O trabalho realizado, para além dos resultados diretos esperados junto aos adolescentes, possibilitou fortalecer os laços entre o setor saúde e o setor educação em nível local, assim como ajudou a fortalecer os debates sobre a saúde mental na AB. Fomentar outras práticas nas equipes significa avançar no caminho da promoção da saúde. Houve inclusive convites à equipe para ações em outras escolas no âmbito do PSE. No entanto, algumas dificuldades no processo devem ser apontadas, como dificuldade no acesso aos familiares e responsáveis pelos adolescentes, com o tempo disponível tendo se revelado insuficiente para esta vinculação. Ademais, o desafio da continuidade das ações de cuidado se fez presente nesta eSF, após decorridos oito meses de início do projeto.

Após episódios de intimidação e ameaças de pessoas armadas na UBS, a gestão da AB fechou a unidade por um período e, a partir desse momento, houve a desconstrução da equipe, sem que houve esforços para cuidar e fortalecer as equipes atuantes na região, profundamente afetadas pelo medo da violência do tráfico armado daquela localidade. Ao contrário, verificou-se um ensejo para o esvaziamento de mais um ponto de atenção àquelas vulnerabilidades, configurando-se aí a reprodução da violência institucional, marcada pela negação de direitos fundamentais.

A psicóloga e a fisioterapeuta que compunham o projeto, não estando como profissionais essenciais da eSF, não puderam voltar à equipe, apesar dos esforços coletivos, inclusive com a participação da comunidade escolar, que pedia a continuidade do trabalho. Nesse contexto, manifesta-se também a vulnerabilidade institucional a que equipes, dispositivos e práticas de $\mathrm{AB}$ estão expostos, com a recente desconstrução dos programas e projetos desse nível de cuidado, fortalecendo a cronicidade e agudização dos adoecimentos, perpassados pelas condições de vida e de trabalho de usuários e profissionais do SUS.

Porém, é importante ressaltar que as condições e possibilidades vivenciadas permitiram conhecer, pensar e criar práticas e percursos de cuidado, dando movimento e potencialidade às forças de trabalho disponíveis. Dentre tais condições, destacaram-se a autonomia e a emancipação, as quais guiaram o trabalho e trouxeram satisfação pela produtividade e pela maior conscientização. Afinal, quando se pode inventar e participar 
ativamente das ações não se fica à deriva ou determinado pelos estigmas. Finaliza-se esse relato inserindo a integralidade no ritmo rap, ao elucidar que quando se trata de conhecer e atuar sobre as necessidades biológicas, psicológicas, ambientais e sociais de crianças e adolescentes "é tudo pra ontem", como bem diz a canção de Emicida (2020).

\section{REFERÊNCIAS}

ARAÚJO, Ulisses Ferreira. A construção social e psicológica dos valores. In: ARAÚJO, Ulisses Ferreira; PUIG, Josep Maria, ARANTES, Valeria Amorim (Orgs.) Educação e valores: pontos e contrapontos. 2. ed. São Paulo: Summus, 2007, p. 1-13.

AYRES, José Ricardo de Carvalho Mesquita; FREITAS, Ângela Carvalho; SANTOS, Marco Antônio Silva; SALETTI FILHO, Haroldo César; FRANÇA-JÚNIOR, Ivan. Adolescência e Aids: avaliação de uma experiência de educação preventiva entre pares. Interface Comunicação, Saúde, Educação, Botucatu, v. 7, n. 12, p. 113-28. 2003.

BARBIANI, Rosangela. Violação de direitos de crianças e adolescentes no Brasil: interfaces com a política de saúde. Saúde Debate, Rio de Janeiro, v. 40, n. 109, p. 200-211, jun. 2016.

BRASIL. Lei no 8.069, de 13 de julho de 1990. Dispõe sobre o Estatuto da Criança e do Adolescente e dá outras providências. Diário Oficial da República Federativa do Brasil, Brasília, DF, 16 jul. 1990.

BRASIL. Ministério da Saúde. Política Nacional de Promoção da Saúde. Brasília, DF, 2006.

BRASIL. Decreto no 6.286, de 5 de Dezembro de 2007. Institui o Programa Saúde na Escola - PSE, e dá outras providências. Diário Oficial da União. 6 dez 2007.

BRASIL, Ministério da Saúde. Portaria No 2.446/GM de 11 de Novembro de 2014. Redefine a Política Nacional de Promoção da Saúde. Brasília, DF, 2014.

BRASIL, Ministério da Saúde. Portaria no 2.436 de 21 de setembro de 2017. Aprova a Política Nacional de Atenção Básica, estabelecendo a revisão de diretrizes para a organização da Atenção Básica, no âmbito do Sistema Único de Saúde (SUS). Brasília, 2017.

BOURDIEU, Pierre. O poder simbólico. Rio de Janeiro: Bertrand Brasil, 1989, 311p. BUSS, Paulo Marchiori; PELLEGRINI FILHO, Alberto. A Saúde e seus Determinantes Sociais. Physis: Revista Saúde Coletiva, Rio de Janeiro, v. 17, n. 1, 77-93, 2007. 
CAMPANATI, Cynthia Conceição Schmidt. Enfrentamento do medo da violência social urbana em duas unidades de Atenção Básica de Itaguaí-RJ. 94 p. Dissertação (Mestrado em Saúde Pública) - Escola Nacional de Saúde Pública Sergio Arouca, Fundação Oswaldo Cruz, Rio de Janeiro, 2018.

CASEMIRO, Juliana Pereira; DA FONSECA, Alexandre Brasil Carvalho; SECCO, Fabio Vellozo Martins. Promover saúde na escola: reflexões a partir de uma revisão sobre saúde escolar na América Latina. Ciência e Saúde Coletiva, v. 19, n. 3, p. 829-840, 2014.

DOMINGUES, Adriana Rodrigues; PEREIRA, Adriana Fernandes Lellis; OLIVEIRA, Ana Carolina; ABRANTES, Cristina Gonçalves; CARDOSO, Tiago Henrique; MOURA, Vanessa Alice. As principais violações de direitos de crianças e adolescentes em Heliópolis - São Paulo/Brasil. Desidades, Rio de Janeiro, n. 19, abr./ jun., 2018.

EMICIDA - É Tudo Pra Ontem. In: Emicida, É Tudo pra Ontem, Laboratório Fantasma. 2020 .

FREIRE, Paulo. Pedagogia do Oprimido. 18. ed. Rio de Janeiro: Paz e Terra, 1983., 184p.

FREIRE, Paulo. Pedagogia da Autonomia: saberes necessários à prática educativa. 35 . ed. São Paulo: Paz e Terra, 2007, 144p.

GOMES, Claudia de Moraes; HORTA, Natália de Cássia. Promoção de saúde do adolescente em âmbito escolar. Revista de APS - Atenção Primária à Saúde, Juiz de Fora, v. 13, n. 4, p. 486-499, out./dez. 2010.

HURTADO, Daniela Haertel. Projetos de vida e projetos vitais: um estudo sobre projetos de jovens estudantes em condição de vulnerabilidade social da cidade de São Paulo. 170 p. Dissertação (Mestrado em Educação) - Faculdade de Educação da Universidade de São Paulo, São Paulo, 2012.

IBGE - Instituto Brasileiro de Geografia e Estatísticas por estado e cidade. 2021.

INEP - Instituto Nacional de Estudos e Pesquisas Educacionais Anísio Teixeira Educação Básica, Censo Escolar. 2020.

ISP - Instituto de Segurança Pública. Governo do estado do Rio de Janeiro. 2021.

LOPES, Iraneide Etelvina; NOGUEIRA, Júlia Aparecida Devidé; ROCHA, Dais Gonçalves. Eixos de ação do Programa Saúde na Escola e Promoção da Saúde: revisão integrativa. Saúde Debate, Rio de Janeiro, v. 42 n. 118, jul./set. 2018.

MINAYO, Maria Cecília de Souza. Violência social sob a perspectiva da saúde pública. Cadernos de Saúde Pública, Rio de Janeiro, v. 10, p. 07-18. 1994.

MINAYO, Maria Cecília de Souza. Violência e Saúde. Rio de Janeiro: FIOCRUZ, 2006. $132 \mathrm{p}$.

MINAYO, Maria Cecília de Souza; SOUZA, Edinilsa Ramos; SILVA, Marta Maria Alves; ASSIS, Simone Gonçalves. Institucionalização do tema da violência no SUS: avanços e desafios. Ciência e Saúde Coletiva, Rio de Janeiro. v. 23, n. 6, jun. 2018. 
MISSE, M. Crime e Violência no Brasil Conteporâneo: Estudos de Sociologia do crime e da violência urbana. Rio de Janeiro: Lumen Juris, 2006, 300p.

NAVARRO, Antônio. Tempo escolar e a violência autodirigida: fortalecimento da autoestima em adolescentes. Trabalho de Conclusão de Curso (Especialização em Tecnologias Educacionais para Prática Docente no Ensino da Saúde na Escola) - Escola Nacional de Saúde Pública Sergio Arouca, Fiocruz. Franca, 2019.

NJAINE, Kathie; MINAYO, Maria Cecília de Souza. Violência na escola: identificando pistas para a prevenção. Interface, Botucatu v. 7 n. 13, ago. 2003.

OMS - Organização Mundial da Saúde. Relatório de um Grupo de Estudos da OMS sobre Jovens e "Saúde para Todos no Ano 2000". Genebra, 1986. 120p.

PRATES, Elton Junio Sady; PRATES, Maria Luiza Sady; SILVA, Laís Figueiredo Inácio; FERREIRA, Glaucia Marina Furini; ARAÚJO, Luana Matos Silva; ANDRADE, Raquel Dully. Oficinas educativas junto a adolescentes em situação de vulnerabilidade social: promoção da saúde, cidadania e empoderamento. Expressa Extensão, Universidade Federal de Pelotas, v. 24, n. 3, p. 79-90, set./dez, 2019.

SILVA, Marta Angélica Iossi; MELLO, Flávia Carvalho Malta; MELLO, Débora Falheiros; FERRIANI, Maria das Graças Carvalho; SAMPAIO, Juliane Messias Cordeiro; OLIVEIRA, Wanderlei Abadio. Vulnerabilidade na saúde do adolescente: questões

contemporâneas. Ciência e Saúde Coletiva, Rio de Janeiro, v. 19, n. 2, p. 619-627, fev. 2014.

STARFIELD, B. Atenção Primária: equilíbrio entre necessidades, serviços e tecnologia. Brasília: Ministério da Saúde, UNESCO, 2002. 177p.

TEIXEIRA, Carmem Fontes. Enfoques teórico-metodológicos do planejamento em saúde. In: TEIXEIRA, Carmem Fontes (Org). Planejamento em saúde - conceitos, métodos e experiências. Salvador: EDUFBA, 2010, p. 17-32.

VALADÃO, Patrícia Aparecida da Silva; LINS, Liliane; CARVALHO, Fernando Martins. Melhor no passado: a verdadeira saúde da família. Saúde e sociedade, [online], v. 28, n. 1, p. 193-206, 2019.

Submetido: 03/06/2021

Aprovado: 26/08/2021 